\title{
ASSESSMENT AND MANAGEMENT OF LEVEL CROSSING RISKS
}

The goal of the project "Assessment and Management of Level Crossing Risks" was to make a comprehensive analysis of safety of level crossings in the Moravian-Silesian Region. The project is divided into several phases including technical and legislative aspects as well as issues of human factor affecting the occurrence of incidents related to level crossings. In individual chapters, results of questionnaire survey concerning the given problems are processed, the analysis of level crossing risks is made and measures to reduce the risks associated with level crossing traffic are proposed.

\section{Introduction}

In the Czech Republic many casualties and injuries are still connected with level crossings. The high death and injury rates of level crossing traffic in the Czech Republic are given above all by the historical development of the number of level crossings, i.e. places where a railway line crosses a road or path, and by the present-day increase in road traffic. For this reason, the Union for the Development of the Moravian-Silesian Region and the Czech Technology Platform on Industrial Safety gave impetus to the project Assessment and Management of Level Crossing Risks in which also the Railway Infrastructure Administration (henceforth referred to as SŽDC) participated.

\section{Level Crossings}

(1) A level crossing according to Act No. 266/1994 Coll., on rail systems as subsequently amended [1] is defined as a point of a railway crossing with a surface road at the level of rails. In the mentioned Act, Section 6, it is stated that if the railway is crossing a road at the level of rails, the rail transport operation shall have the right of way over the transport on road communications. Each level crossing regardless the type of level crossing must be equipped with a crossbuck or another type of crossing safety device. If all standards, decrees and regulations on the design, construction and maintenance of level crossings are fulfilled, level crossings can be regarded as safe. In spite of the fact that the above-mentioned legal aspects are satisfied, many people die annually of just level crossing accidents.

Rate of Level Crossing Accidents in the Moravian-Silesian Region

One of regions with a high risk of railway accidents is the Moravian-Silesian Region (furthermore referred to as MSR). In the ter- ritory of MSR 647 level crossings falling within the scope of SZDC Ostrava are there (see Table 1).

Overview of level crossings in MSR

Table 1

Overview of level crossings on lines in MSR - by type of safety device

\begin{tabular}{|l|l|}
\hline Crossings equipped merely with a crossbuck & 398 \\
\hline
\end{tabular}

Crossings equipped with a crossing safety device (CSD)

\begin{tabular}{|l|r|r|}
\hline - Crossings equipped with warning lights - total & 235 & 249 \\
\hline - Crossings equipped with a mechanical CSD & 14 & \\
\hline Total number of crossings & \multicolumn{2}{|c|}{647} \\
\hline
\end{tabular}

In the years 2005-2009, 101 accidents occurred at these crossings; 56 persons were injured, 19 persons died and altogether the value of damage to property was more than CZK $16.5 .10^{6}[2,5,6]$. The numbers of accidents in individual years in the given area are presented in Table 2.

Number of collisions at level crossings

Table 2 in MSR in the years 2005-2009[2]

\begin{tabular}{|c|c|c|c|c|c|c|}
\hline Number of collisions at level crossings in MSR in the years 2005-2009 \\
\hline \multirow{2}{*}{ Means } & \multicolumn{7}{|c|}{ Year } \\
\cline { 2 - 7 } & 2005 & 2006 & 2007 & 2008 & 2009 & total \\
\hline car & 22 & 20 & 9 & 11 & 13 & 74 \\
\hline lorry & 2 & 1 & 2 & 2 & 0 & 7 \\
\hline motorcycle & 0 & 0 & 1 & 1 & 1 & 3 \\
\hline cyclist & 1 & 1 & 1 & 0 & 2 & 5 \\
\hline pedestrian & 2 & 4 & 0 & 1 & 4 & 11 \\
\hline
\end{tabular}

\footnotetext{
* I. Zitnikova, L. Malerova, R. Pribyl, M. Schwarz, A. Bernatik, L. Kopecka Department of Safety Management, Faculty of Safety Engineering, VSB-Technical University of Ostrava, Czech Republic, E-mail: iva.zitnikova@seznam.cz
} 
To assess the accident rate in this region, rather detailed analyses for the period of last five years, i.e. the years 2005-2009, were carried out. As an example, Graph 1 is given below.

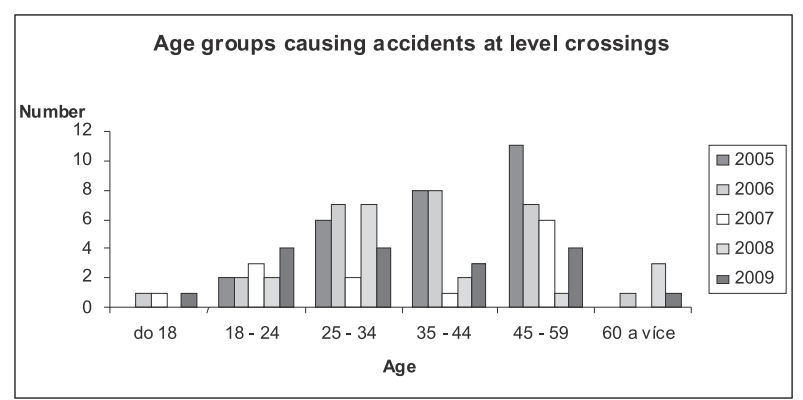

Graph 1: Age influencing the number of accidents at level crossing in the years 2005-2009 [2]

\section{Perception of Level Crossing Risks}

Each road traffic participant knows what traffic lights look like, what the meaning of their signalling is, and knows what to do when the red, yellow and green lights are on. However what is the cause of that fact that red lights at level crossings are not perceived and respected in the same degree as red lights at crossroads? If we think about this, consequences of showing little respect for them at level crossings are usually more serious than at crossroads [6, 7].

This behaviour and perception of possible risks to drivers and also other road traffic participants at level crossings and at crossroads became a stimulus to conducting a questionnaire survey.

\section{Questionnaire Survey}

The aim of questionnaire survey was to define and specify the road traffic participants at level crossings who took part in the questionnaire survey, to evaluate the knowledge of road traffic participants in the area of level crossings, to evaluate the influence of external conditions and stereotype on the satisfaction of level crossing regulations and the view of road traffic participants of perception of level crossing risks.

To accomplish the set objectives, the method of sociological survey, namely written questioning, was used. The questionnaire was anonymous and comprised 13 closed questions.

\section{Results of Questionnaire Survey}

Altogether 340 questionnaires were sent to respondents in the period from the beginning of July to the end of September in the year 2010; 175 questionnaires were returned completed.

Participants in the survey were men and also women of various age groups, with different lengths of driving experience. From the evaluation of the questionnaires it followed that two thirds of respondents were men; the 25-34 year old group was the largest.
The most of respondents met level crossings mainly as drivers having more than 5 years of driving experience; also other level crossing users participated (pedestrians and engine drivers).

From the questionnaire it has been found that respondents e.g.

- consider a level crossing to be a crossroads

- have most frequently failed to notice and crossed a level crossing equipped with a crossbuck

- know the speed with which they are permitted to enter a level crossing

- state that the most frequent cause of failing to notice signs and markings and of passing through a level crossing is the fact that the driver is in a hurry and ignores traffic signs and markings

- do not know any campaign focused on level crossing safety.

\section{Analysis of Level Crossing Risks}

The first step in the process of reducing risks is naturally the analysis of the risks. The risk analysis is usually understood as a process of determination of threats, probability of implementation of these threats and their consequences, i.e. the determination of risks and severity of the risks. The risk analysis becomes the decisive basis for the process of elimination of level crossing risks.

\section{Risk Analysis Procedure}

In the first stage, it was necessary to define the boundaries that would be used for the risk analysis. For the needs of risk analysis, these boundaries were divided into 2 areas: legislative framework $\mathrm{x}$ level crossing itself, its borders. Furthermore, level crossing traffic participants had to be defined generally, i.e. road traffic participants as well as railway traffic participants. The following step was the specification of dangerous substances (toxic, combustible, explosive, and others). For the needs of the risk analysis, substances were divided into liquid and gaseous substances. The kind and type of chosen substances correspond best to materials transported by road as well as by rail. The last step was the determination of the order of individual methods in making the risk analysis. The following procedure was proposed:

1. application of What - If method,

2. application of FMEA method,

3. application of FTA method.

\section{Results of Risk Analysis}

When making the risk analysis, the following scenarios were evaluated:

a) an accident between a tank lorry transporting a dangerous substance and a passenger train (in combination with the injury of participants and release of dangerous substance - 1A - 1D),

b) an accident between a tank lorry and a goods train - both transporting dangerous substances (in combination with the injury of participants and release of dangerous substance $2 \mathrm{~A}-2 \mathrm{D})$,

c) an accident between a car and a passenger train (with / without the injury of participants - 3A - 3B)

d) an accident between a bus and a passenger train (with / without the injury of participants - 4A - 4B) 


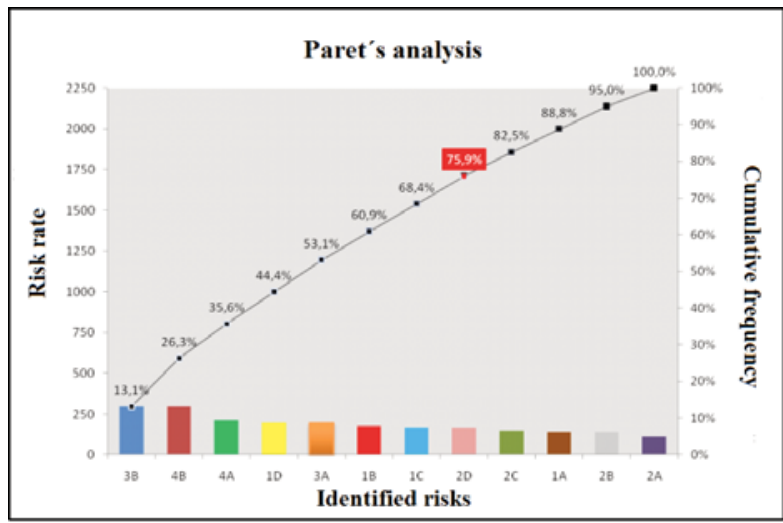

Graph 2: Paret's analysis

From the above-mentioned and made analyses it has followed that the most severe risks are:

A crash between a tank lorry transporting dangerous substances and a passenger train:

- involving the injury of participants and involving no release of dangerous substance - 1B

- involving no injuries of participants and involving the release of dangerous substance - $1 \mathrm{C}$

- involving the injury of participants and the release of dangerous substance - 1D

In this part it is clear that the most important factor is the number of directly affected people as a consequence of potential accident/traffic accident at the level crossing (either direct endangering passengers' health, or endangering the health of driver of the tank lorry due to the accident or the release of dangerous substance).

A crash between a tank lorry transporting a dangerous substance and a goods train transporting a dangerous substance:

- involving the injury of passengers and the release of dangerous substance - 2D

In this case it is necessary to consider two factors, namely the probability of the collision between the tank lorry transporting a dangerous substance and the goods train transporting a dangerous substance. This probability is quite small, but consequences that may occur in case of crash may be fatal for both the driver/engine driver and the surroundings of the level crossing (population in the vicinity of the level crossing and contamination of the environment).

\section{A crash between a car and a passenger train:}

- involving no injury of accident participants - 3A

- involving the injury of accident participants - 3B

Here the important factor is the high probability of accident occurrence, because the frequency of cars is the highest of those of all the above-mentioned transport means, and also because in the evaluation of data on level crossing accidents the majority of level crossing accidents were caused by drivers of cars.

A crash between a bus and a passenger train:

- involving no injury of accident participants - 4A

- involving the injury of accident participants - 4B

As a consequence of crash between a bus and a passenger train, a high number of people are potentially endangered. Many passengers may be injured and killed. With such incident, a difficult intervention of fire brigades and the emergency treatment of injured persons by emergency medical service are connected. People who are participants in such an accident may suffer psychical injury/ trauma that will accompany them for their whole lives. As a consequence they will not be able to go by such means (bus, train) any more in order to avoid the same situation.

\section{Proposed Measures}

The proposed measures following from the comprehensive solving of problems of level crossings could be divided, according to their character, into the following three groups: technical measures, organisational measures and educational measures. The specific groups are characterised and analysed below.

\section{1) Technical Measures}

Technical measures are such measures that eliminate the occurrence of a fault. They should be as cheap as possible, but yet effective.

\section{a) Replacement of Gate}

An effective way to prevent the entry to the crossing is to replace the existing protection gate by another type of barrier that should completely prevent the entry. This is of course very expensive but proven, e.g. in Spain. Crossings are protected here by means of rising posts. The level crossing is equipped with an optical and an acoustic signalling device; after their activation, the posts become to rise from the ground. This type of protection has replaced the existing gate (barrier).

In the Czech Republic this type of protection is not entirely unknown. It can be met on roads, but not at level crossings. The advantages of application of such protection equipment to level crossings are an increase in safety and the prevention of entry of
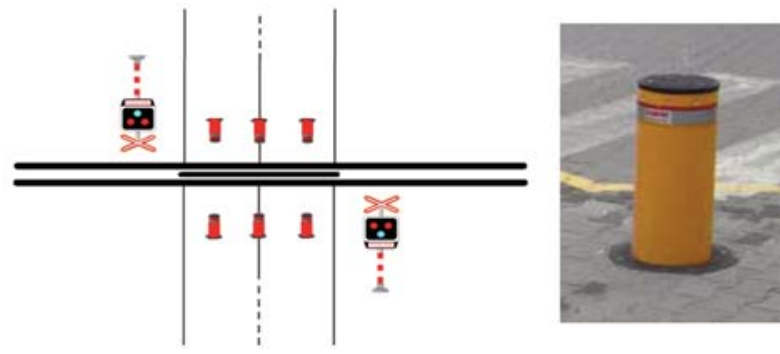

Fig. 1: Rising posts 
vehicles to level crossings. The disadvantages of this piece of equipment are the costs of purchase and assembly.

\section{b) Change in Type of Optical Signalling Device}

As for light signalling devices, it would be suitable to use diodes instead of present-day lights. Diodes can be seen better even when blinded by sun glare, in fog, in conditions of poor visibility, and others.

New indicators using LED technology have already been tested in the Czech Republic. By testing it has been found that the lights can be seen in sharp sunshine much better; even from the extreme angles of view, when the light of lamps is less visible. The advantages are the longer life of LEDs and the fact that each of three lights of the indicator is fitted with 137 LEDs that are electronically divided into three independent circuits - segments. In case of fault in one circuit, the remaining LEDs (about $90 \mathrm{pcs}$ ) emit light sufficient for fulfilling standards and regulations on the luminous intensity of indicators. [3]

\section{c) Change in Traffic Signs}

For the selected level crossings with an increased number of traffic accidents we recommend using a warning traffic board "Caution, frequent accident level crossing" (see Figure 2) similarly to road traffic, where in the selected parts there are traffic signs warning of frequent accident points. The designed traffic sign could be classed to the group of warning traffic signs and designated as sign No. A 34; in combination with the traffic sign No. A 31c it could ( $80 \mathrm{~m}$ ahead of crossing) warn of a level crossing at which traffic accidents occur frequently.
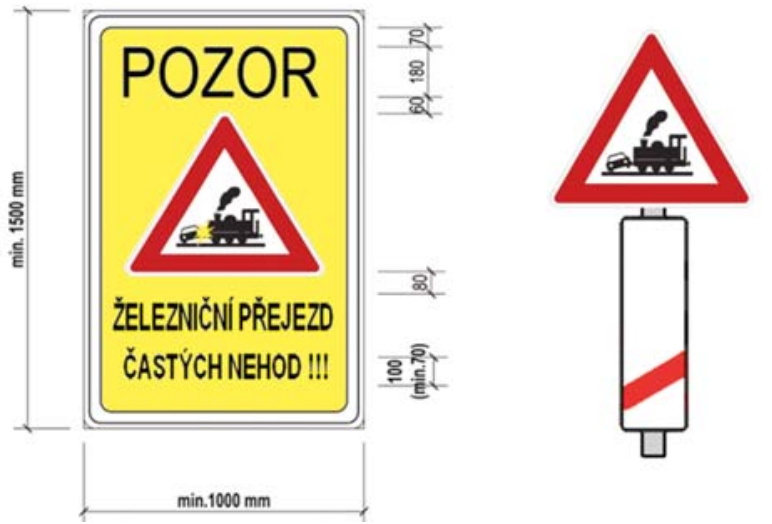

Fig. 2 Design of traffic sign "Caution, frequent accident level crossing"

\section{d) Making Traffic Signs More Conspicuous}

An important point is also making level crossing signs more conspicuous. It would be suitable to use red reflex reflectors, which can be seen better by drivers in conditions of poor visibility, instead of red stripes.

e) Additional Markings
To additional markings, light guide strips (cat's eyes) belong. A light strip would either draw the attention of drivers to the level crossing permanently, or the lights would be switched on after activation of the crossing safety device by a coming rail vehicle. Before the level crossing, drivers would be warned by means of a row of high-intensity LED warning lights placed across the road. Another possible way of road marking would be the use of so-called "optical-psychological brake" with acoustic effect, such as several stripes running across the road before a level crossing. These manners have already been dealt within a project of Ministry of Transport [4].

\section{f) Camera System and Dummy Cameras}

An effective way to prevent passing through level crossings after activation of signalling devices is the installation of cameras that begin recording simultaneously with the activation of signalling devices or shortly before the activation. If the driver is aware that his/her behaviour is being observed, his/her behaviour is more responsible and in accordance with regulations. This manner of prevention is already utilized in some places; however, this way is very difficult from the organisational point of view (records must be checked, drivers breaking regulations must be identified and fined), from the financial point of view and also the point of view of safety. The proper purchase and operation of a camera system is expensive, despite the fact that cameras may be stolen or destroyed. For this reason, cameras could be replaced by dummy cameras, and from time to time, moved from level crossings where they are used to other selected level crossings.

\section{g) To Execute Changes}

The purpose of this measure is to execute such changes in a signalling device and in its immediate surroundings that will be able to disturb the driver's stereotyped acting, such as change in the sound of the signalling device, etc., but that will be in accordance with relevant standards and regulations.

\section{2) Organisational Measures}

Organisational measures should be divided according to their scope of competence and powers.

a) Police of the Czech Republic, Municipal Police

- rather frequent inspection of traffic at level crossings, fining of drivers breaking the road traffic regulations,

- interpretation of camera records,

- organisation of educational actions for children in schools.

b) Employee of SŽDC - Rail Transport Engineer

- to keep regular checks of signs and markings,

- to keep regular checks of sight conditions,

- to keep regular checks of functionality of signalling devices

- all checks should be conducted by a person unfamiliar with the given level crossing and its surroundings to avoid ignoring possible worsened conditions owing to the good knowledge of local conditions and stereotype.

c) In General

- formation of a database on hazardous crossings in the region, 
- clarification of competence, authorities and responsibilities of organisations as for individual safety devices, signs and markings, and others,

- making legislation and recourse stricter in the case of not obeying the regulations of road traffic at level crossings,

- preparation of publications, leaflets on "How to behave at level crossings?" and "How to behave at a level crossing in case of accident?"

- media pressure, better awareness, e.g. of accident rate statistics,

- not to carry out nationwide media campaigns, but to focus on specific areas, regions, because people are more sensitive to and interested in things that happen in their surroundings than at the other end of the country.

\section{3) Educational Measures}

Educational measures are to increase the awareness of people on hazards associated with level crossings, on prevention of these hazards and on how to behave in the case of accident at a level crossing.

The proposals are divided into groups according to the target groups for which they are intended:

- basic schools

- inclusion of educational actions and traffic education in the teaching-learning process in basic schools;

- distribution of instructional films on behaviour at level crossings to schools;

- driving schools

- to increase attention paid to level crossing problems in teaching in driving schools;

- by driving simulators, instructional films drawing attention to hazards by means of information on road traffic regulations when passing through level crossings and information on how drivers and other persons are to behave if being a participant in an level crossing accident (where to call, what to report, etc.);
- the public

- information on behaviour at level crossings intended for drivers and also for pedestrians;

- fining pedestrians, cyclists for going around the closed gate at level crossings.

In the course of implementation of the measures, attention should be paid especially to feedback. This means that after a given time period, tests and surveys will be carried out that will verify the efficiency of measures implemented.

\section{Conclusion}

The goal of the project on the topic "Assessment and Management of Level Crossing Risks" dealt with for several months was to make a comprehensive analysis of safety of level crossings in the Moravian-Silesian Region, covering technical as well as legislative aspects and also human factor issues.

Of the above-mentioned proposed measures to reduce risks, the following measures are recommended preferentially:

- Increase in the level of protection of level crossings (installation of gates);

- Making level crossing additional signs and markings more conspicuous (optically and acoustically);

- Improvement of awareness and education of road traffic participants (campaigns, driving schools, pupils of basic schools and students of secondary schools).

This contribution was prepared as part of the grant project of Student Grant Competition of VŠB - Technical University of Ostrava, No. SP/2010126 "Assessment and Management of Level crossing Risks".

\section{References}

[1] Act No. 266/1994 Coll. runways, as amended, and editing (in Czech)

[2] Internal materials provided from the Railway Infrastructure Administration (in Czech)

[3] Roads and railways, transport (in Czech) [online]. [cited 2010-10-01] http://www.silnice-zeleznice.cz/clanek/poprve-v-cr-vlakoveprejezdy-s-led-vystrazniky/

[4] Typing increase security level crossings, design of organizational and technical - construction measures (in Czech) [online]. [cited 201009-20] 〈www.mdcr.cz/NR/rdonlyres/19E3EDAE.../Typizaceprejezdy.doc>

[5] CIGANIK, L., BALASICOVA, I.: Protection and Defence of Railway Transport against International Terrorism, In: Communications - Scientific Letters of the University of Zilina, No. 1, 2008

[6] WOLANIN, J., M.: Perceiving, Drama, Discomfort - Shadow of Disaster, In: Communisations - Scientific Letters of the University of Zilina, No. 3, 2005

[7] GERLICI, J., LACK, T., ONDROVA, Z.: Evaluation of comfort for passengers of railway vehicles, In: Communications - Scientific Letters of the University of Zilina, No. 3, 2008. 